Editorial

\title{
Pathways to Low Carbon Building: Reflection on the Special Issue
}

\author{
Alice Moncaster \\ Interdisciplinary Design for the Built Environment, Department of Engineering, University of Cambridge, \\ Cambridge CB2 1PZ, UK; E-Mail: amm24@cam.ac.uk; Tel.: +44-1223-760117
}

Received: 18 June 2015 / Accepted: 23 June 2015 / Published: 25 June 2015

\begin{abstract}
In 2014, this journal invited me to edit a special issue on low carbon building. We put out a call for papers that offered new perspectives, crossing boundaries between technical and social research approaches. The six papers selected and published have emanated from university departments and research centres of Engineering, Architecture, Energy, Design, Urban Planning, Environment, and Sustainable Building. Together they represent a unique and highly readable snapshot of the multiple approaches to this crucial issue-but they also do more; read as a whole they allow the reader to draw new conclusions about the way forward. This editorial draws together and reflects on the six papers, concluding with recommendations for urgent and vital actions for policy makers, professionals and academics.
\end{abstract}

Keywords: low carbon building; pathways; transitions; built environment; socio-technical research

\section{Introduction}

The need to reduce carbon from buildings is becoming increasingly critical ([1], chapter 9). However, the problem is complex: carbon is emitted from energy use during the operational phase of buildings, but also from the production of materials and from the construction, refurbishment, demolition, and end of life phases [2,3]. There are multiple policies, regulations, financial mechanisms, tools, and certification schemes designed to encourage carbon reduction [4-7]; within this framework the carbon impact of a building is determined by individual and collective decisions taken by clients, designers, and contractors, and by the occupiers throughout the lifetime of the building [8-10]. The ways in which these decision-makers understand and engage with the problem are further influenced 
by personal and professional interpretations, values and practices, and by commercial and political interests $[11,12]$.

The Special Issue of this journal on Low Carbon Building Deign represents some of the latest understanding of this complex field. Papers with quantitative assessments of the carbon emissions from different building designs, and the (theoretical or actual) reductions, which can be realized both from the operational and embodied impacts, have been frequently (and usefully) published elsewhere (see for example [13-15]). Here, we have chosen instead to publish six papers which each cross different disciplinary boundaries, together developing an understanding of carbon emissions from buildings as an inherently multi-dimensional, socio-technical problem. In doing so, the papers offer an insight into the breadth of methodological and theoretical perspectives employed to study this single issue, and provide an excellent collective introduction from which to develop an interdisciplinary understanding.

Starting with an exploration of the roles of particular actors within this context, Rachael Luck's paper considers the overlap between the design process and the use of buildings, with a particular focus on the impact that architects can have on the subsequent energy behavior of building users, through careful briefing on the building design [16]. Barthelmes et al. [17] consider a different overlap that of the effect on energy efficient building design of including cost optimization, as instructed by the recast Energy Performance of Buildings Directive (EPBD). Both papers consider the architect's role, and propose that it must now be recognized as having expanded far beyond its traditional realm. Most professionals who have worked in building design for a number of years will be familiar and broadly in agreement with their conclusion, which suggests important implications for professional architectural education.

The above two papers focus on the design of new buildings; however, within many developed countries in particular, awareness is growing of the need to simultaneously focus on improving the energy efficiency of the existing building stock. Janda et al. [18] look at domestic refurbishment, comparing the policies and industry responses in the UK and France, and considering multiple "middle" perspectives including that of the architect. Godoy-Shimizu et al. [19] also consider energy use in existing domestic buildings, investigating, as does Luck, the impact of the end user. Their paper conducts a socio-technical analysis of energy use in homes, and draws conclusions about the correlations between social indicators and energy use, which are highly relevant to policy formation in this area.

However policy must not only respond to current states. In the particular case of reducing whole life carbon emissions and energy use from buildings, which have an inherently long life span, it is crucial to consider the impacts of possible futures, including both changes of use and changing climatic conditions. This is the subject of Christina Georgiadou's paper, which uses a qualitative study of building practitioners to consider how a futures perspective might be incorporated into current building regulation and policy [20]. Finally Ronald Rovers also looks to the future, and considers the long term impact that taking "zero carbon building" as a design mantra will have on our values and concerns both as a design community and as a society [21].

The papers are reviewed in more detail in the sections below. A collective conclusion is drawn in the final section, followed by some wide-reaching implications and recommendations for policy, practice and research. 


\section{Perspectives on Low Carbon Building}

In "Learning How to Use Buildings", Rachael Luck discusses how design conversations between architects and the future occupiers of the social housing developments they are designing can be used to increase understanding about low energy living [16]. A careful ethnographic study over five months of meetings and workshops reveals basic misunderstandings about now common technologies, including heating and water recycling systems, as well as the role that the conversations have in improving understanding. What comes across is not a one way knowledge transfer from the architect-professional to the resident-lay participants, but instead a co-production of knowledge; more informed residents help to reassure and teach others, while the architects develop a better understanding of how the building they are designing will be occupied. The process is revealed, as Luck explains, as a pedagogic opportunity to discuss technologies and how to use them effectively to reduce energy consumption. It is also something more intangible and social, in which the events themselves "engender a community-minded ethos". Whether this will also help to develop a lower carbon lifestyle is unexplored. However, although as Luck acknowledges there are many causes of the gap between design and actual energy performance of buildings, her research reveals a potentially effective route for addressing one important part of the problem.

Barthelmes et al. [17] look instead at how to design low carbon buildings, by testing the methodology set out in the recast EU Energy Performance of Buildings Directive for the calculation of "cost-optimal levels for energy performance requirements" ([17], p. 938). The authors use the methodology to test a number of design scenarios with different thermal envelopes and heating/ventilation (HVAC) options for a low energy building, applying it as an early-stage design-decision tool. Incorporating considerations of costs in this manner, they suggest, will require new skills of the architect, who needs to take on additional roles as both "energy consultant and financial expert". Their conclusion is cautiously positive - the methodology does support the design of buildings with lower whole life costs and a reduced impact on the environment, as might be expected. However perhaps surprisingly, the cost optimal solution is revealed to be that with a significant upfront investment in onsite renewable energy sources, including $7 \mathrm{~kW}$ photovoltaic panels and an ultra-high efficiency (coefficient of performance of 4.75) heat pump. The model is perhaps worth testing against the actual performance of systems in practice, although this was not the objective of this particular paper. The authors do sound a note of caution about the complexity of the process, noting that the application of "cost-optimality... is far from easy and straightforward" ([17], p. 959), and calling for the need for a more simple assessment tool for use at preliminary design stages. In spite of identifying this limitation and others (for example the omission of any assessment of the carbon emissions at the end of life), the authors conclude that, "It seems clear that an increase of analyses will lead to more reliable final design choices" ([17], p. 960). This certainly seems to be the route down which both regulators and designers are inclined to go, but the evidence is not yet clear.

It seems from both papers reviewed so far that the need for low carbon buildings is resulting in the development of new demands on architects, and of a corresponding need for new skills. Janda et al. [18] expand this area, exploring "how the need for low carbon refurbishment might change the roles of building professionals". Focusing on refurbishment rather than new build, they acknowledge that the actors are likely to be small and medium-sized enterprises, including general and specialist builders 
and subcontractors, as well as design professionals. Their paper is concerned in particular with interactions between these "middle actors", and between them and policy makers, clients and homeowners, and the subsequent impacts on carbon reduction that innovations within this part of the process can have elsewhere. This is a carefully argued and conscientiously referenced paper which is used to draw some important conclusions about the future of the industry; these include the need for higher quality products and processes, increased integration at all levels, better communication and a new level of professional education. None of these conclusions are radically new, but they are well-supported here with some real and thought-provoking studies of how change is currently happening on the ground.

It is the behavior of home-owners which is instead the concern of Godoy-Shimizu et al. [19], who analyze the results from the Household Electricity Survey. This UK Government-sponsored programme surveyed electricity use in 250 homes between 2010 and 2011, metering individual appliances at ten-minute intervals for up to a year, and also asking the householders for social information such as age and occupation. Godoy-Shimizu et al. [19] have provided a careful and thought-provoking analysis of this most detailed dataset yet on UK domestic electricity use, full of useful and highly readable graphs, such as those showing the electricity use throughout typical week days and weekend days, due to ten different appliance-types (Figure 3 in [19]). Some of their findings are surprising, such as the high proportion of peak-load (6-7 p.m.) electricity use due to lighting, leading to their recommendation that policy should focus on improving efficiency of light fittings rather than looking for smart "load shifting" strategies. The combined social and technical data allows them to identify the social groups that are the highest and lowest users of electricity, but also point out that within these groups the usage is not uniform across all types of appliance. They also demonstrate the range of electricity use within specific appliance types-one example they offer is that 17 households used less than $100 \mathrm{kWh}$ per year on audiovisual appliances, while 22 households used more than $1000 \mathrm{kWh}$, or ten times this amount. The paper concludes with a number of policy recommendations, as well as a plea for further and more detailed surveys of this nature, to provide a stronger evidence base for intervention strategies.

Returning to the realm of design, Georgiadou [20] calls our attention to the critical importance of incorporating "future-proofing" into the design of housing developments. She uses her paper to develop a definition of the term as "sustainable, low-energy buildings, able to accommodate social, technological, economic, environmental, and regulatory changes over the long-term, thus maximizing lifecycle value". The paper then develops a number of design approaches to tackle some of these issues, and through interviews with industry practitioners reviews which of these are currently considered feasible, reasonably feasible or unfeasible. One particular side issue, which is discussed at some length, is the use of tools, both broad regulatory tools such as the UK Code for Sustainable Homes, and the technical design tools such as the Standard Assessment Procedure (SAP) for the demonstration of energy efficiency. While the interviewees suggested that the SAP model was insufficiently accurate to predict a building's operational energy performance, there was equally a concern that tools which calculated embodied energy were difficult to implement because they were too complex (in addition to several other factors). These conflicting messages beg the question as to whether any tool which is capable of incorporating sufficient intricacy in its model will necessarily become too complex to be usable. By extension, any tool which is too simplistic and single-issue 
might end up influencing decisions which result in higher, rather than lower, carbon emissions over the lifetime of a building. Is there still a role for single-issue tools in this environment?

This is an inherently complex and multi-faceted problem, and the author, while doing an excellent job of identifying and categorizing the multiple issues, does not attempt to over-simplify; the paper and the conceptual model developed within it are worth careful reading.

The final paper is offered by Rovers [21], who provides a futuristic insight into a world "on the eve of major changes", in which the current focus on reducing operational energy has reached its zenith. In this world, where zero carbon buildings have been achieved through a combination of increased energy efficient fabric and maximized provision of zero carbon energy on site (the outcome encouraged by current policy, as identified by Barthelmes et al. [17]), Rovers considers what then will be the issues left to consider? His answer is used to point out the failings in our current approach. Zero (operational) carbon in buildings will only be achieved through a huge increase in use of materials, which itself has implications for carbon emissions, as the extraction, production and transport of all materials is still primarily enabled through fossil fuel use. Not only will true "zero carbon" never be reached through this approach, there are also a multitude of other environmental and social implications which we are ignoring in this single-minded quest. Rovers points out the implications for resource depletion in particular, noting that the availability of metals, for example, is already becoming critical, meaning in turn that energy use in extraction of the remaining ore is increasing. Rovers ends his paper with a call to the building sector to make "a paradigm shift in the approach and evaluation of resource use" [21].

\section{Discussion and Conclusions}

To start the discussion, I would ask you to consider a concept which appears in the introduction of three of the six papers in this special issue, and has frequently been repeated elsewhere. Barthelmes et al. [17] state that "the building sector is responsible for more than $40 \%$ of total energy consumption", while Janda et al. [18] claim "the residential sector is the largest energy consumer across Europe", and Godoy-Shimizu et al. [19] point out that "homes account for more than a quarter of the national [UK] energy use and carbon dioxide emissions". I suggest that we need to consider carefully what we mean by these phrases. Who, exactly, is responsible for this energy use and associated carbon emissions? And most importantly what actions towards their reduction should be taken, and by whom?

Regulation to date has implicitly defined the answer as lying almost entirely with the design community. Designers are urged towards demonstrating ever greater (net) reductions of operational carbon emissions. These are to be achieved through increasing levels of insulation and air tightness, ever more complex heating, ventilation and lighting systems, and the addition of new on site "renewable" energy technologies; the carbon reductions thus realized are to be demonstrated through the use of increasingly complex software modelling tools, requiring increasingly specialist (and therefore expensive) skills sets. Even the acknowledgement that occupiers have a part to play in the energy they use in buildings has been framed such that it is the designers' responsibility and professional duty to carry our post occupancy evaluation (POE) to assess how the building is being used (see for example [22-24]). This technological framing has two inevitable results; first that 
reducing carbon from buildings necessarily requires greater expense; and secondly that the solution to the problem is thereby defined as belonging solely to the (technical) building designers.

Each in a different way, the papers in this issue contest this singular approach, and together suggest a more complex answer. Luck [16], for instance, shows that designers can have only a limited impact on energy use, even when supported through early design stage conversations between architects and residents. Janda et al. [18] discuss the additional important role of the multiple "middle-actors" such as builders. Godoy-Shimizu et al. [19] disaggregate the different uses of electricity in homes, using this to identify the limited areas in which design can have any substantial impact. Georgiadou [20] points out the importance of occupier-behavior in operational carbon emissions, and furthermore highlights the exclusion of embodied carbon emissions from regulations, even though this is potentially the area in which designers might have the greatest impact. Rovers [21] draws our gaze to a future where this focus on designing "zero [operational] carbon" buildings has been taken to its unhappy conclusion. He also points out that to date the regulations and our subsequent actions have not resulted in any noticeable reduction of fossil fuel use or carbon emissions.

So what then is the answer? Clearly design professionals do have a significant role to play, but through changed processes, as well as products. The papers suggest that these should include a reconsideration of responsibilities, a blurring of professional identities and disciplinary boundaries, and an increase in lay participation in design [16-18,20]. More effective modelling tools and more comprehensive data will also be needed, as well as a clearer understanding by practitioners of the limitations of what can be modelled and what can't $[17,19,20]$. Lifecycle thinking is fundamental, including incorporating an understanding of the (whole life) embodied carbon of buildings and building materials, as well as understanding more about how energy is used and carbon emitted during occupation, alongside a consideration of the impacts of future climates and social needs [19-21]. Finally Rovers prompts us to remember that, in our important focus on low carbon building design, we cannot neglect the other equally important environmental, material resource, and social implications of our resultant actions [21].

Further than this we need not just to change the way we do things, but also to change the way we think about the problem. Rather than continuing to identify carbon reduction as a technical problem with a technical solution, to be provided by a design team increasingly split into different technical specialisms, we instead need to develop a conceptual model which understands energy use in the built environment in terms of its diverse and complex social, political and technical interactions. Inherent within this model is an assumption that everyone involved-designer, builder, client, policy maker, occupier, and researcher - must acknowledge their collective responsibility for energy use and carbon emissions in the built environment, and for the co-creation of the solutions.

Academics have a crucial part to play in this transition to a low carbon society. We must continue to produce a rigorous evidence base, developing a multiple interdisciplinary analysis of low carbon building, and to present our evidence in an accessible language, as the six papers presented in this special issue have done. But further, we must behave as a catalyst to develop wider understanding through interaction and co-production of knowledge with our students, with building professionals, with policy makers and with members of the public. There are a few excellent instances where this occurs. We need more. 


\section{Conflicts of Interest}

The author declares no conflict of interest.

\section{References}

1. Intergovernmental Panel on Climate Change. Climate Change 2014: Impacts, Adaptation, and Vulnerability; Cambridge University Press: Cambridge, UK; New York, NY, USA, 2014.

2. Ibn-Mohammed, T.; Ozawa-Meida, L.; Greenough, R.M.; Taylor, S.; Acquaye, A. Operational vs. embodied emissions in buildings-A review of currenttrends. Energy Build. 2013, 66, 232-245.

3. Moncaster, A.M.; Symons, K.E. A method and tool for "cradle to grave" embodied energy and carbon impacts of UK buildings in compliance with the new TC350 standards. Energy Build. 2013, 66, 514-523.

4. Sunikka, M.M. Policies for Improving Energy Efficiency in the European Housing Stock; TU Delft: Delft, The Netherlands, 2006.

5. Ürge-Vorsatz, D.; Koeppel, S.; Mirasgedis, S. Appraisal of policy instruments for reducing buildings' $\mathrm{CO}_{2}$ emissions. Build. Res. Inf. 2007, 35, 458-477.

6. Burman, E.; Mumovic, D.; Kimpian, J. Towards measurement and verification of energy performance under the framework of the European directive for energy performance of buildings. Energy 2014, 77, 153-163.

7. Foxell, S.; Cooper, I. Closing the policy gaps. Build. Res. Inf. 2015, 43, 399-406.

8. Lovell, $\mathrm{H}$. The role of individuals in policy change: The case of UK low energy housing. Environ. Plan. C 2009, 27, 491-511.

9. Elmualim, A.; Shockley, D.; Valle, R.; Ludlow, G.; Shah, S. Barriers and commitment of facilities management profession to the sustainability agenda. Build. Environ. 2010, 45, 58-64.

10. Davies, P.J.; Emmitt, S.; Firth, S.K. Challenges for capturing and assessing initial embodied energy: A contractor's perspective. Constr. Manage. Econ. 2014, 32, 290-308.

11. Fischer, J.; Guy, S. Re-interpreting regulations: Architects as intermediaries for low-carbon buildings. Urban Stud. 2009, 46, 2577-2594.

12. Rydin, Y.; Holman, N.; Hands, V.; Sommer, F. Incorporating sustainable development concerns into an urban regeneration project: How politics can defeat procedures. J. Environ. Plan. Manag. 2003, 46, 545-562.

13. Sartori, I.; Hestnes, A.G. Energy use in the life cycle of conventional and low-energy buildings: A review article. Energy Build. 2007, 39, 249-257.

14. Ramesh, T.; Prakash, R.; Shukla, K.K. Life cycle energy analysis of buildings: An overview. Energy Build. 2010, 42, 1592-1600.

15. Stephan, A.; Crawford, R.H.; de Myttenaere, K. Towards a comprehensive life cycle energy analysis framework for residential buildings. Energy Build. 2012, 55, 592-600.

16. Luck, R. Learning how to use buildings: An exploration of the potential of design interactions to support transition to low-impact community living. Buildings 2014, 4, 963-977. 
17. Barthelmes, V.M.; Becchio, C.; Marta, C.; Corgnati, S.P. The influence of energy targets and economic concerns in design strategies for a residential nearly-zero energy building. Buildings 2014, 4, 937-962.

18. Janda, K.; Killip, G.; Fawcett, T. Reducing carbon from the "middle-out": The role of builders in domestic refurbishment. Buildings 2014, 4, 911-936.

19. Godoy-Shimizu, D.; Palmer, J.; Terry, N. What can we learn from the household electricity survey? Buildings 2014, 4, 737-761.

20. Georgiadou, M. Future-proofed energy design approaches for achieving low-energy homes: Enhancing the code for sustainable homes. Buildings 2014, 4, 488-519.

21. Rovers, R. Zero-energy and beyond: A paradigm shift in assessment. Buildings 2014, 5, 1-13.

22. Cohen, R.; Standeven, M.; Bordass, B.; Leaman, A. Assessing building performance in use 1: The probe process. Build. Res. Inf. 2001, 29, 85-102.

23. Leaman, A.; Stevenson, F.; Bordass, B. Building evaluation: Practice and principles. Build. Res. Inf. 2010, 38, 564-577.

24. Cohen, R.; Bordass, B. Mandating transparency about building energy performance in use. Build. Res. Inf. 2015, 43, 534-552.

(C) 2015 by the author; licensee MDPI, Basel, Switzerland. This article is an open access article distributed under the terms and conditions of the Creative Commons Attribution license (http://creativecommons.org/licenses/by/4.0/). 